\title{
Laparoscopic liver resection for the patients with hepatocellular carcinoma and chronic liver disease
}

\author{
Zenichi Morise \\ Department of Surgery, Fujita Health University School of Medicine, Toyoake, Aichi, Japan \\ Correspondence to: Zenichi Morise, MD, PhD, FACS, AGAF. Department of Surgery, Fujita Health University School of Medicine, 1-98 \\ Dengakugakubo Kutsukakecho Toyoake, Aichi, Japan. Email: zmorise@fujita-hu.ac.jp.
}

\begin{abstract}
Liver resection (LR), liver transplantation (LT), transarterial chemoembolization, and local ablation therapy are the treatment options for hepatocellular carcinoma (HCC). Although LR, LT and local ablation therapy (only for small tumor) provide the best hope for cure, most patients with HCC have also chronic liver disease (CLD) backgrounds, including HCV-liver cirrhosis. Therefore, they are at high risk for development of postoperative complications—sometimes fatal—and metachronous multicentric recurrent tumors occurring from the preneoplastic CLD background. Appropriate treatment is selected for HCC patients, on the combined evaluations of tumor condition and liver function. However, not small number of patients cannot undergo any treatment option due to poor liver function and/or complicated tumor condition. After repeated treatments, it can happen more often. It is thought that the features of laparoscopic LR could lead to the expansion of the LR indication to those patients, in the settings of severe CLD, repeat LR and bridging to LT. In our experience, Child-Pugh (CP) score is one of the promising candidates as a selection indicator which correlates well to our indication criteria of surface small laparoscopic LR to severe CLD patients, patient's performance status, and prognosis. Portal hypertension should be also counted in the selection criteria.
\end{abstract}

Keywords: Hepatocellular carcinoma (HCC); hepatectomy; laparoscopic surgery; liver cirrhosis

Received: 09 June 2018; Accepted: 29 June 2018; Published: 16 July 2018.

doi: $10.21037 / \operatorname{tgh} .2018 .07 .01$

View this article at: http://dx.doi.org/10.21037/tgh.2018.07.01

\section{General therapeutic situation of the patients with hepatocellular carcinoma (HCC) patients and chronic liver disease (CLD), including HCV liver cirrhosis}

HCC is one of most common primary cancer and most common cause of cancer-related deaths in the world $(1,2)$. Liver resection (LR) (3), liver transplantation (LT) (4), transarterial chemoembolization, and local ablation therapy (5) are the treatment options for the disease. Although LR, LT and local ablation therapy (only for small tumor) provide the best hope for cure (5-8), most patients with HCC have also CLD backgrounds, including HCV-liver cirrhosis. Therefore, they are at high risk for development of postoperative complications-sometimes fatal—and metachronous multicentric recurrent tumors occurring from the preneoplastic CLD background.

In addition to the oncological therapeutic effects, the degree of invasive stress, especially that affecting the diseased liver, and residual liver function should be considered at the consideration of the treatment options for HCC patients with CLD. Patients with CLD have various symptoms (9) and in a high risk following anesthesia and surgery according to their Child-Pugh (CP) class $(10,11)$. For severe CLD patients, refractory ascites can be often occurred even after limited LR and lead to fatal complications $(12,13)$.

Currently, the choice of LR, LT, local ablation therapy or transarterial chemoembolization is made based on each patient's tumor condition and liver function (14). However, not a small number of patients with HCC and CLD cannot undergo any such option because of poor liver function and/ 
or complicated tumor condition. After repeated treatments, it can happen more often.

Among the treatment options mentioned above, LT should be ideal for HCC patients with CLD in the aspect of removing both existing tumors and injured/preneoplastic underlying liver. However, it cannot be applied on a large scale due to the high prevalence of HCC and the donor shortage (15). LT application with immunosuppression afterward is also limited to the patients who have minimal risk of tumor recurrence (16). Expansion of the LT indication for HCC patients is now in its trial stage and controversial $(17,18)$. Therefore, LR has traditionally been accepted as the preferred treatment for the patients with resectable HCC and adequate liver reserve $(8,19,20)$.

Considerable progress in screening, early diagnosis, treatment of CLD, and surgical techniques has expanded the indications of LR during a couple of decades (21). Improvements of the assessment for liver function and understanding of liver anatomy by the sophisticated imaging studies, as well as surgical techniques, are most important impacts on the decreasing mortality rate of HCC; today, the 5-year survival is expected in the range of $38-61 \%$ (22). However, less than $30 \%$ of the patients undergo LR even nowadays $(23,24)$.

Emerging laparoscopic LR (LLR) $(25,26)$ may lead to expand the indication of LR in the therapeutic system for HCC patients with CLD. In this article, the current reports on LLR for HCC patients with CLD are reviewed and our experiences are described.

\section{LLR for the patients with HCC/CLD and repeat resection}

The beginnings of LLR were at the start of the 1990s, with its initial reports (27-29) being published in 1991 and 1992. Thereafter, the indication of LLR has been expanded as a less invasive procedure than open LR (OLR). LLR has the same benefits as other laparoscopic procedures, such as earlier intake, recovery and discharge, and reduced postoperative pain (30). An early meta-analysis of 26 studies found that, although LLR had longer operation time, there were no differences in oncologic outcomes compared to OLR (31). Furthermore, studies showed the specific advantages of LLR, smaller amount of blood loss, shorter portal clamp time, and less overall and liver-specific complications, for selected patients and within the technical capabilities of each experienced center.

The safety and feasibility of LLR and its short-term benefits for the patients with HCC and CLD have also been demonstrated (32-34). LLR may be especially advantageous for the patients of severe CLD, who often develop refractory ascites after OLR, a potentially fatal complication $(12,13)$. LLR has the advantage of minimal ascites, due to the preservation of venous and lymphatic collateral flows (35), which reduces the risk of water/electrolyte imbalance and hypoproteinemia that could lead to fatal liver failure. This feature should be the most noteworthy advantage of LLR.

Patients who undergo LR are exposed to three different types of stresses: (I) general, whole-body surgical stress; (II) reduced liver function due to reduced liver volume after resection; (III) surgery-induced injury to the environment surrounding the liver and liver parenchyma (caused by disruption of the collateral blood and lymphatic flows with laparotomy and mobilization and mesenchymal injury with compression) (36). Reduction of the third surgery-induced injuries by LLR, especially in the patients with HCC and CLD, decreases the risk of refractory ascites. That facilitates a smoother recovery without liver failure.

The impact of LLR on this issue depends on the severity of the CLD, the operative technique (extent of dissection of the peritoneal attachments and adhesions), and extent of resection. Our previous study compared the shortterm outcomes of liver surface small LLR for the patients with severe CLD [CP-B or -C and indocyanine green retention rate at $15 \mathrm{~min}$ (ICGR15) $\geq 40 \%$ ] to those for the patients with mild-moderate CLD (35). Although the study was a small, retrospective unmatched study, it revealed comparable perioperative outcomes, including postoperative ascites, between patients with severe and mild-to-moderate CLD in LLR. This is an important difference from OLR.

LLR also allows for better visibility and manipulation in a small operative field under some conditions, such as repeat hepatectomy with adhesions (34). Laparoscopic surgery makes subsequent surgeries easier by the reduction of adhesions (37). It was reported that the salvage transplantation after previous LLR is associated with reductions of operation time, blood loss, and transfusion requirements, compared to that after OLR (38). Treatment of recurrence is another major issue for the patients with HCC and CLD, as they harbor potential for multicentric metachronous lesions occurring from the CLD background. Modifications of the anatomy and the formation of adhesions increases the difficulty of repeat LR. Several studies compared LLR and OLR in the setting of repeat LR $(39,40)$. The operation time of repeat LLR in patients undergone LLR as the initial surgery was significantly 
Table 1 Treatment options with hope for cure for HCC patients with CLD (Modification from World f Gastroenterol. 2014;20:14381-92)

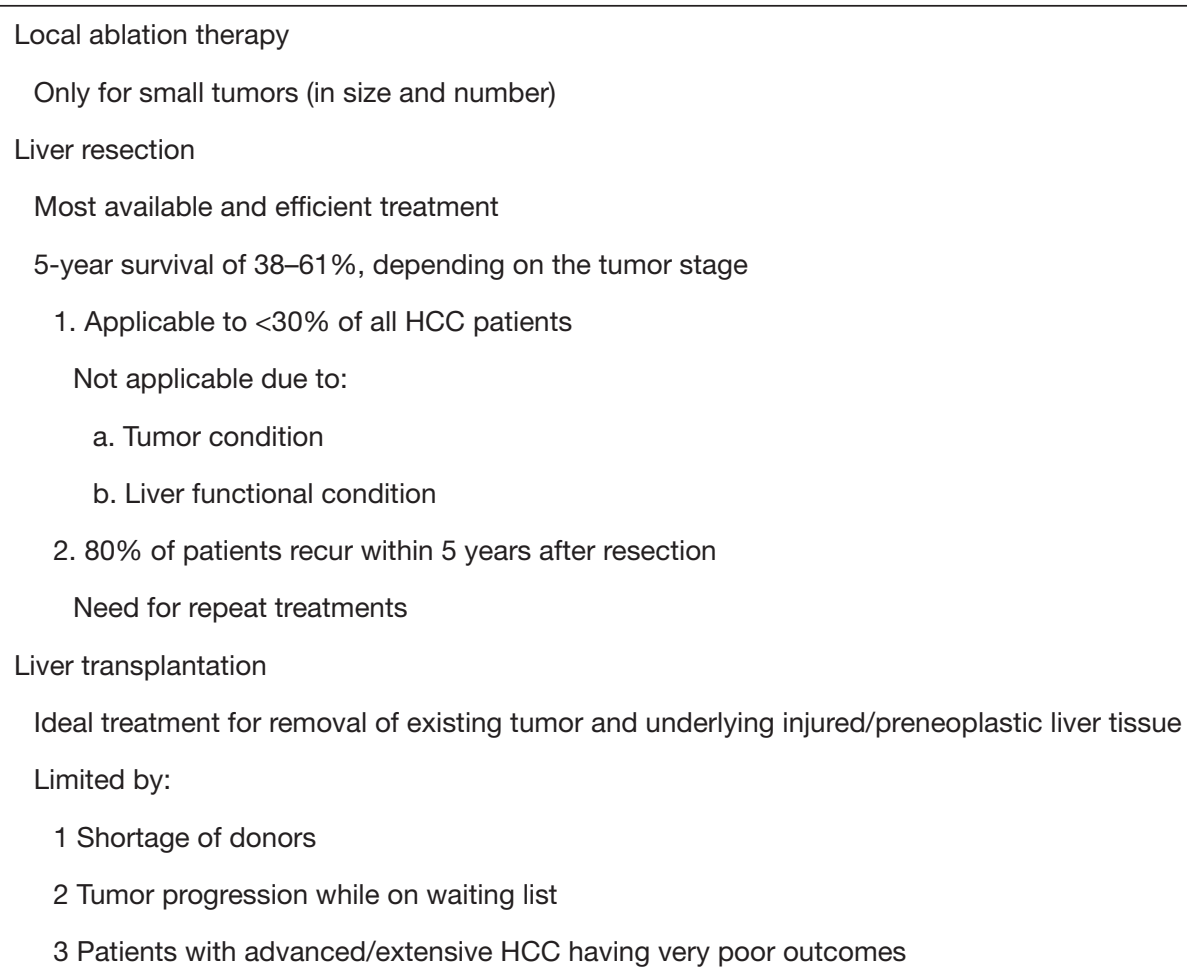

Note: laparoscopic liver resection, with its unique approach (i.e., good visualization and manipulation capacities) could help to overcome the problems listed. Specifically, for liver resection 1-b by low incidence of ascites and liver failure, for liver resection 2 in its production of less adhesions and reduced need for adhesiolysis at repeat resection (easy access to repeat resection), and for liver transplantation 2 as a bridging therapy. CLD, chronic liver disease; HCC, hepatocellular carcinoma.

shorter than that in patients undergone initial OLR. On the other hand, regardless of the initial approach, repeat LLR was associated with reduced blood loss, reduced transfusion rates, reduced postoperative complications, and a shorter hospital stay, compared to repeat $\operatorname{OLR}(39,40)$. It can be translated that LLR is advantageous not only in producing fewer adhesions but also in reducing the needs for adhesiolysis in repeat LR. As mentioned above, the laparoscopic view and manipulation (41-43) facilitate the better access in a small operative field and lead to the decreased need for adhesiolysis. This could be explained as similar to the advantages of LLR for CLD patients noted above.

The characteristics described above indicate that LLR could be superior than OLR under certain conditions. Also, LLR could be an option as the bridging therapy to LT. The instrumental development and accumulation of surgeon's experience have expanded the indication of LLR (44). Although the number of studies reported has been small and comprising various settings, we believe that the specific features of LLR will expand the indications for LR to HCC patients with background CLD, particularly in the settings of severe CLD, repeat LR and bridging to LT (Table 1).

\section{Indications of LLR to severe CLD patients}

For the treatment selection of HCC, the Barcelona clinic liver cancer (BCLC) staging system/treatment algorithm (45) and the Japan Society of Hepatology clinical guidelines for HCC (JSH guideline) (46) are used in Western countries and Japan, respectively. Both systems include not only tumor condition but also background liver condition for the treatment selection. The two differ in that the BCLC algorithm uses CP classification (47) for assessments of liver function, while the JSH guideline uses the liver damage (LD) classification of the Liver Cancer Study Group of Japan (48), which has ICGR15 as one of the essential elements.

ICGR 15 is a useful modality for assessing hepatic functional reserve and predicting postoperative mortality (49-51). The volume of the liver resected in each patient 
is basically planned according to the tumor condition, including its location (surface or non-surface area, distance from major vessels, etc.) and size. However, HCC patients sometimes develop postoperative liver failure due to poor liver functional reserve after the planned resection. ICGR15 has been an excellent tool for predicting how much liver volume could be resected in each patient's liver condition (50). On the other hand, nontumorous functioning liver parenchyma is resected minimally in liver surface tumorectomy or small partial resection. In those cases, the most important evaluation point is, not how much liver volume could be resected, but whether the patient and the liver could tolerate the surgical stress. As mentioned before, LLR minimizes the surgery-induced injury by the disruption of the collateral circulation and the compression on the liver parenchyma, and leads to decreased postoperative ascites and liver failure (36). The decision-making process during liver surface small partial LLR should be different from the other LRs.

\section{Our experiences of LLR}

We performed 152 LLR for liver tumors. Among these patients, 19 had more than $30 \%$ ICGR 15 and HCC. The details of these patients are presented in Table 2. The 19 patients were composed of 6,11 and 2 patients with CPA, -B and -C, respectively. By LD classification, they included 2, 12 and 5 patients of LD-A, -B and -C, respectively. There was a discrepancy between the liver functional assessments of $\mathrm{CP}$ and LD. The patients with high ICGR15 values tended to be classified into higher grade of liver dysfunction by the LD classification. Based on liver functional criteria only of BCLC and JHS, there were already 2 and 5 patients out of LR indication in this group, respectively. We applied liver surface small LLR to the CP-B/C (up to CP score of 10) patients only when the patients could have been doing light or household labor for more than 6 months before their surgery, in a stable condition (good performance status).

Excluding the 1 patient whose follow-up period is less than 24 months and the 1 patient who underwent LT at 15 months after LLR, 7 patients died of HCC or liver disease within 24 months after LLR (D group). When the $\mathrm{D}$ patients were compared to the group of 10 patients who survived more than 24 months (A group), there are significant difference in the groups' CP scores, but not in the model for end-stage liver disease (MELD) scores (5254), the albumin-bilirubin (ALBI) scores (55), the ICGR15 values and blood platelet counts (Table 3; platelet counts were compared excluding 1 patient after splenectomy from the D group). The values of ICGR15 are similar in the A and D groups. All of the D patients, but only 3 of the $11 \mathrm{~A}$ patients, had esophageal varices before surgery. All of the A patients, excluding the patients with LT at 15 months after LLR, had 50,000 or more blood platelet counts, and 5 out of $7 \mathrm{D}$ patients had below 60,000 .

It is thought that ICGR 15 above $30-40 \%$ is out of their reliable range and not well-correlated with actual liver function. Thus, it may not be suitable for the liver functional selection criteria of surface small LLR in severe CLD patients, even though it is very useful and simple criteria for judging how much liver volume can be resected in the range below $30-40 \%$. Although the difficult judgements for the objective presences of ascites and encephalopathy should be needed, CP score is a promising candidate for selection indicator of surface small LLR in severe CLD patients, correlating well to our indication criteria (patient's performance status) and prognosis after surgery. Portal hypertension (56), indicated by the presence of esophageal varices and low platelet counts, should be also counted in the selection criteria of surface small LLR.

Most reported cases of repeat LLR underwent minor resection for the patients with HCC and CLD, as mentioned before. The impact of anatomical alterations to liver parenchyma and intrahepatic structure from the previous LR could be relatively small in such cases. However, there were 3 patients with anatomical resection or resections exposing major vessels [including S8 segmentectomy after 4-time LLR (57)] after previous anatomical resection who developed postoperative bile leakage and longer postoperative hospital stay, among our 33 repeat and 12 three-or-more-time repeat LLRs. Since alterations of the anatomy and surrounding scars and/or adhesion of major vessel structures should have big impacts on anatomical resection or resections exposing major vessels in repeat LLR after previous anatomical resection, further experiences and evaluations of such repeat LLR are needed.

\section{Conclusions}

Although the number of studies reported has been small and comprising various settings, the specific features of LLR could expand the indications of LR to HCC patients with background CLD, including HCV liver cirrhosis, particularly in the settings of severe CLD and repeat LR. LLR could prolong the overall survival of the patients with HCC and CLD as a powerful local therapy which can 


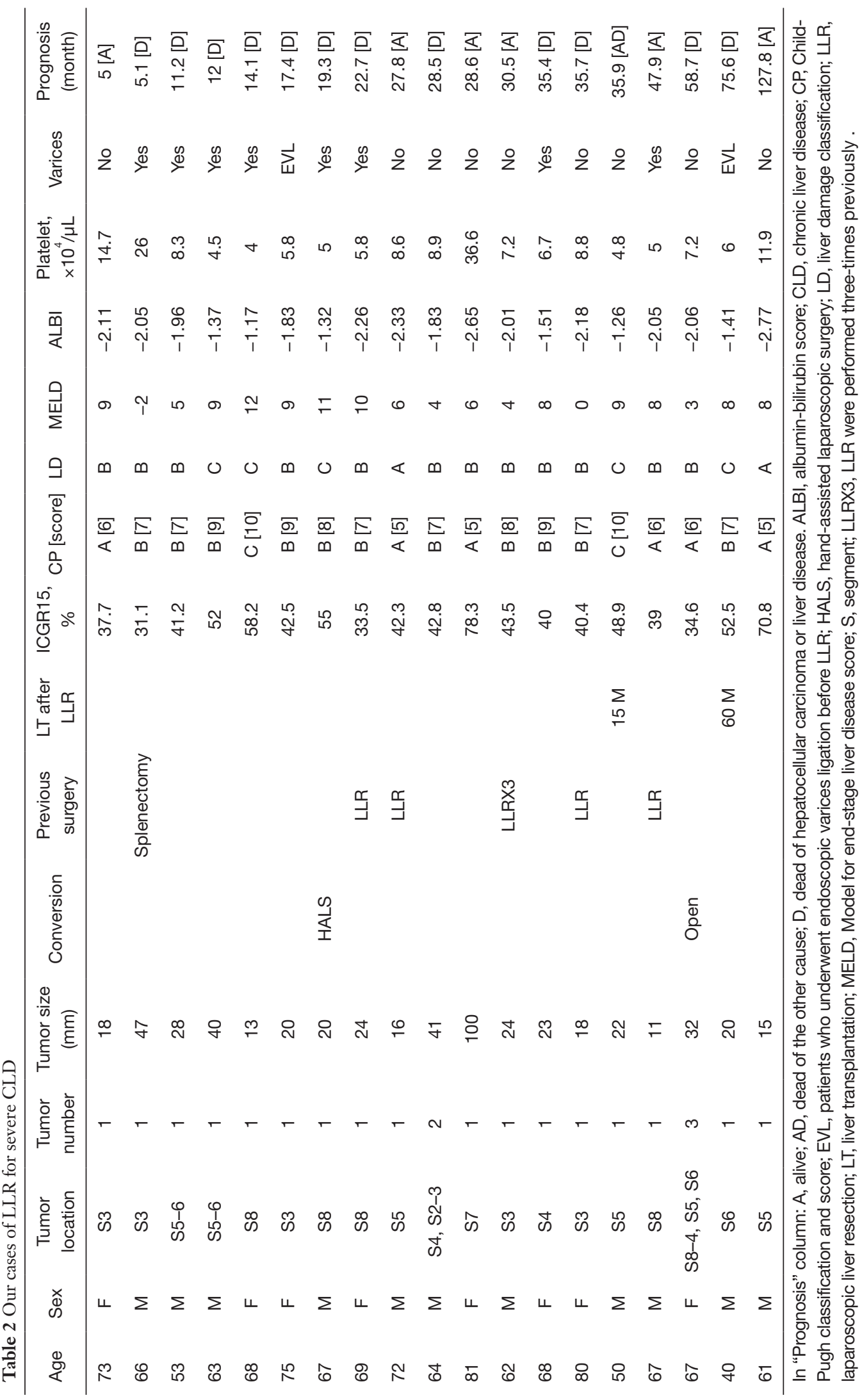


Table 3 Parameters of liver function in the patient groups of those who survived more than 24 months (group A*) and who died of HCC or liver disease within 24 months (group D)

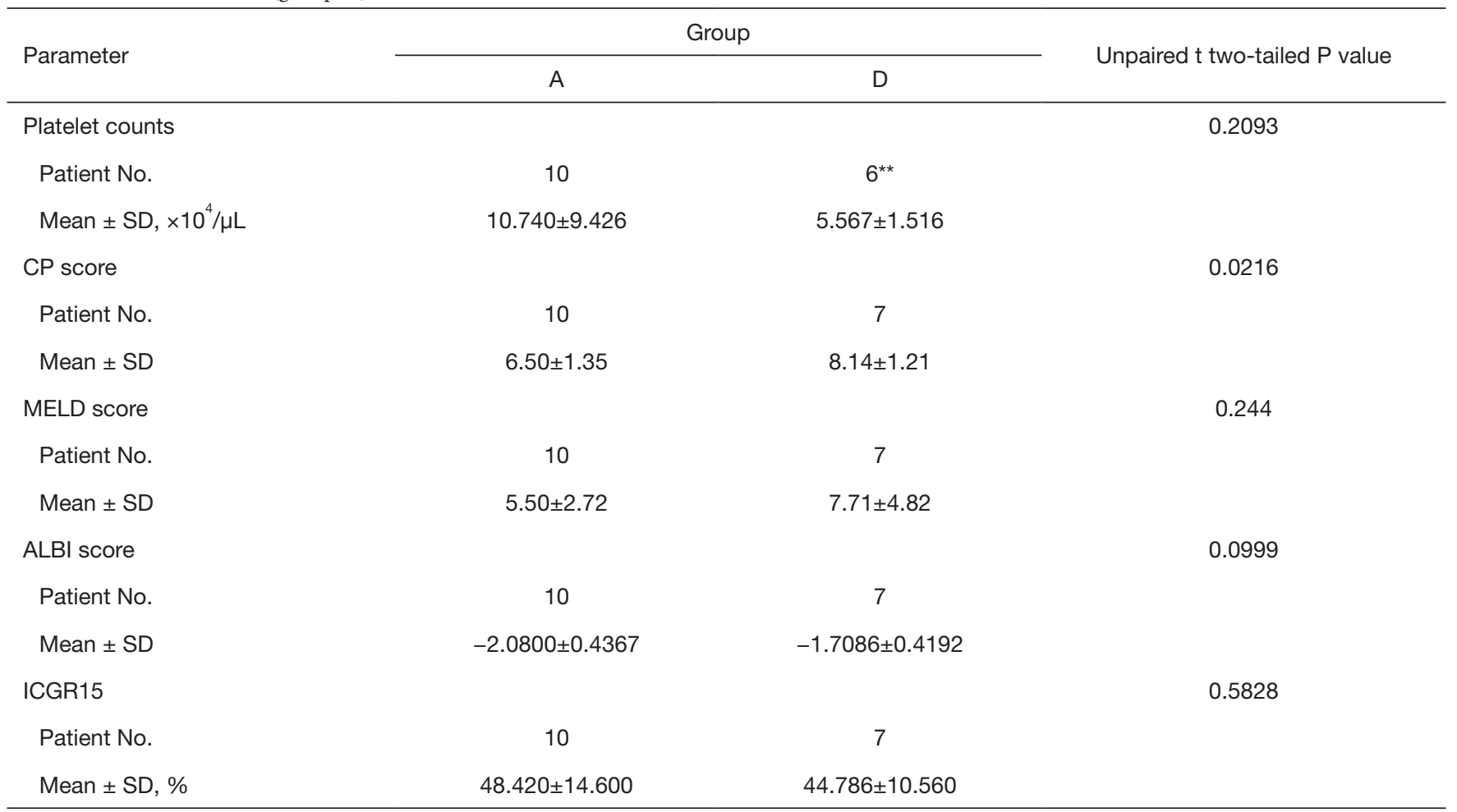

*, 1 patient who underwent liver transplantation at 15 months after LR was excluded from group A; ${ }^{\star \star}$, 1 patient after splenectomy was excluded from group D. ALBI, albumin-bilirubin score; CP, Child-Pugh classification and score; HCC, hepatocellular carcinoma; ICGR15, indocyanine green retention rate at 15 min; LD, liver damage classification; LR, liver resection; MELD, model for end-stage liver disease score.

be applied repeatedly with minimal deterioration of liver function.

\section{Acknowledgements}

None.

\section{Footnote}

Conflicts of Interest: The author has no conflicts of interest to declare.

\section{References}

1. Ferlay J, Soerjomataram I, Dikshit R, et al. Cancer incidence and mortality worldwide: sources, methods and major patterns in GLOBOCAN 2012. Int J Cancer 2015;136:E359-86.

2. Schütte K, Bornschein J, Malfertheiner P.
Hepatocellularcarcinoma--epidemiological trends and risk factors. Dig Dis 2009;27:80-92.

3. Capussotti L, Ferrero A, Viganò L, et al. Liver resection for HCC with cirrhosis: surgical perspectives out of EASL/ AASLD guidelines. Eur J Surg Oncol 2009;35:11-5.

4. Hwang S, Lee SG, Belghiti J. Liver transplantation for HCC: its role: Eastern and Western perspectives. J Hepatobiliary Pancreat Sci 2010;17:443-8.

5. Lau WY, Leung TW, Yu SC, et al. Percutaneous local ablative therapy for hepatocellular carcinoma: a review and look into the future. Ann Surg 2003;237:171-9.

6. Mazzaferro V, Regalia E, Doci R, et al. Liver transplantation for the treatment of small hepatocellular carcinomas in patients with cirrhosis. $\mathrm{N}$ Engl J Med 1996;334:693-9.

7. Ryder SD. Guidelines for the diagnosis and treatment of hepatocellular carcinoma (HCC) in adults. Gut 2003;52:iii1-8.

8. Cha CH, Ruo L, Fong Y, Jet al. Resection of 
hepatocellular carcinoma in patients otherwise eligible for transplantation. Ann Surg 2003;238:315-21.

9. Hoeper MM, Krowka MJ, Strassburg CP. Portopulmonary hypertension and hepatopulmonary syndrome. Lancet 2004;363:1461-8.

10. Ziser A, Plevak DJ, Wiesner RH, et al. Morbidity and mortality in cirrhotic patients undergoing anesthesia and surgery. Anesthesiology 1999;90:42-53.

11. Mansour A, Watson W, Shayani V, et al. Abdominal operations in patients with cirrhosis: still a major surgical challenge. Surgery 1997;122:730-5.

12. Belghiti J, Hiramatsu K, Benoist S, et al. Seven hundred forty-seven hepatectomies in the 1990s: an update to evaluate the actual risk of liver resection. J Am Coll Surg 2000;191:38-46.

13. Lai EC, Fan ST, Lo CM, et al. Hepatic resection for hepatocellular carcinoma. An audit of 343 patients. Ann Surg 1995;221:291-8.

14. Llovet JM, Fuster J, Bruix J. The Barcelona approach: diagnosis, staging, and treatment of hepatocellular carcinoma. Liver Transpl 2004;10:S115-20.

15. Llovet JM, Fuster J, Bruix J. Intention-to-treat analysis of surgical treatment for early hepatocellular carcinoma: resection versus transplantation. Hepatology 1999;30:1434-40.

16. Cucchetti A, Vitale A, Gaudio MD, et al. Harm and benefits of primary liver resection and salvage transplantation for hepatocellular carcinoma. Am J Transplant 2010;10:619-27.

17. Yao FY, Ferrell L, Bass NM, et al. Liver transplantation for hepatocellular carcinoma: Expansion of the tumor size limits does not adversely impact survival. Hepatology 2001;33:1394-403.

18. Fujiki M, Takada Y, Ogura Y, et al. Significance of desgamma-carboxy prothrombin in selection criteria for living donor liver transplantation for hepatocellular carcinoma. Am J Transplant 2009;9:2362-71.

19. Bruix J, Reig M, Sherman M. Evidence-based diagnosis, staging, and treatment of patients with hepatocellular carcinoma. Gastroenterology 2016;150:835-53.

20. Bruix J, Castells A, Bosch J, et al. Surgical resection of hepatocellular carcinoma in cirrhotic patients: prognostic value of preoperative portal pressure. Gastroenterology 1996;111:1018-22.

21. Rahbari NN, Mehrabi A, Mollberg NM, et al. Hepatocellular carcinoma: current management and perspectives for the future. Ann Surg 2011;253:453-69.

22. Torzilli G, Belghiti J, Kokudo N, et al. A snapshot of the effective indications and results of surgery for hepatocellular carcinoma in tertiary referral centers: is it adherent to the EASL/AASLD recommendations?: an observational study of the HCC East-West study group. Ann Surg 2013;257:929-37.

23. El-Serag HB, Marrero JA, Rudolph L, et al. Diagnosis and treatment of hepatocellular carcinoma. Gastroenterology 2008;134:1752-63.

24. Forner A, Reig ME, de Lope CR, et al. Current strategy for staging and treatment: the BCLC update and future prospects. Semin Liver Dis 2010;30:61-74.

25. Buell JF, Cherqui D, Geller DA, et al. The international position on laparoscopic liver surgery: The Louisville Statement, 2008. Ann Surg 2009;250:825-30.

26. Wakabayashi G, Cherqui D, Geller DA, et al.

Recommendations for laparoscopic liver resection: a report from the second international consensus conference held in Morioka. Ann Surg 2015;261:619-29.

27. Reich H, McGlynn F, DeCaprio J, et al. Laparoscopic excision of benign liver lesions. Obstet Gynecol 1991;78:956-8.

28. Katkhouda N, Fabiani P, Benizri E, et al. Laser resection of a liver hydatid cyst under videolaparoscopy. Br J Surg 1992;79:560-1.

29. Gagner M, Rheault M, Dubuc J. Laparoscopic partial hepatectomy for liver tumor. Surg Endosc 1992;6:99.

30. Viganò L, Tayar C, Laurent A, et al. Laparoscopic liver resection: a systematic review. J Hepatobiliary Pancreat Surg 2009;16:410-21.

31. Mirnezami R, Mirnezami AH, Chandrakumaran K, et al. Short- and long-term outcomes after laparoscopic and open hepatic resection: systematic review and metaanalysis. HPB 2011;13:295-308.

32. Belli G, Fantini C, Belli A, et al. Laparoscopic liver resection for hepatocellular carcinoma in cirrhosis: longterm outcomes. Dig Surg 2011;28:134-40.

33. Morise Z, Kawabe N, Kawase J, et al. Pure laparoscopic hepatectomy for hepatocellular carcinoma with chronic liver disease. World J Hepatol 2013;5:487-95.

34. Tranchart H, Di Giuro G, Lainas P, et al. Laparoscopic resection for hepatocellular carcinoma: a matched-pair comparative study. Surg Endosc 2010;24:1170-6.

35. Morise Z, Sugioka A, Kawabe N, et al. Pure laparoscopic hepatectomy for hepatocellular carcinoma patients with severe liver cirrhosis. Asian J Endosc Surg 2011;4:143-6.

36. Morise Z, Ciria R, Cherqui D, et al. Can we expand the indications for laparoscopic liver resection? A systematic review and meta-analysis of laparoscopic liver resection for 
patients with hepatocellular carcinoma and chronic liver disease. J Hepatobiliary Pancreat Sci 2015;22:342-52.

37. Soubrane O, Goumard C, Laurent A, et al. Laparoscopic resection of hepatocellular carcinoma: a French survey in 351 patients. HPB (Oxford) 2014;16:357-65.

38. Laurent A, Tayar C, Andréoletti M, et al. Laparoscopic liver resection facilitates salvage liver transplantation for hepatocellular carcinoma. J Hepatobiliary Pancreat Surg 2009;16:310-4.

39. Kanazawa A, Tsukamoto T, Shimizu S, et al. Laparoscopic liver resection for treating recurrent hepatocellular carcinoma. J Hepatobiliary Pancreat Sci 2013;20:512-7.

40. Belli G, Cioffi L, Fantini C, et al. Laparoscopic redo surgery for recurrent hepatocellular carcinoma in cirrhotic patients: feasibility, safety, and results. Surg Endosc 2009;23:1807-11.

41. Tomishige H, Morise Z, Kawabe N, et al. Caudal approach to pure laparoscopic posterior sectionectomy under the laparoscopy-specific view. World J Gastrointest Surg 2013;5:173-7.

42. Soubrane O, Schwarz L, Cauchy F, et al. A conceptual technique for laparoscopic right hepatectomybased on facts and oncologic principles: the caudal approach. Ann Surg 2015;261:1226-31.

43. Wakabayashi G, Cherqui D, Geller DA, et al. Laparoscopic hepatectomy is theoretically better than open hepatectomy: preparing for the 2 nd International Consensus Conference on Laparoscopic Liver Resection. J Hepatobiliary Pancreat Sci 2014;21:723-31.

44. Morise Z, Wakabayashi G. First quarter century of laparoscopic liver resection. World J Gastroenterol 2017;23:3581-8.

45. Bruix J, Sherman M, American Association for the Study of Liver Diseases. Management of hepatocellular carcinoma: An update. Hepatology 2011;53:1020-2.

46. Kudo M, Izumi N, Kokudo N, et al. Management of hepatocellular carcinoma in Japan: Consensus-Based Clinical Practice Guidelines proposed by the Japan Society of Hepatology (JSH) 2010 updated version. Dig Dis 2011;29:339-64.

47. Pugh RN, Murray-Lyon IM, Dawson JL, et al. Transection

doi: $10.21037 / \operatorname{tgh} .2018 .07 .01$

Cite this article as: Morise Z. Laparoscopic liver resection for the patients with hepatocellular carcinoma and chronic liver disease. Transl Gastroenterol Hepatol 2018;3:41. of the oesophagus for bleeding oesophageal varices. Br J Surg 1973;60:646-9.

48. Omagari K, Ohba K, Kadokawa Y, et al. Comparison of the grade evaluated by "Liver damage" of Liver Cancer Study Group of Japan and Child-Pugh classification in patients with hepatocellular carcinoma. Hepatol Res 2006;34:266-72.

49. Lau H, Man K, Fan ST, et al. Evaluation of preoperative hepatic function in patients with hepatocellular carcinoma undergoing hepatectomy. Br J Surg 1997;84:1255-9.

50. Makuuchi M, Kosuge T, Takayama T, et al. Surgery for small liver cancers. Semin Surg Oncol 1993;9:298-304.

51. Nonami T, Nakao A, Kurokawa T, et al. Blood loss and ICG clearance as best prognostic markers of posthepatectomy liver failure. Hepatogastroenterology 1999;46:1669-72.

52. Malinchoc M, Kamath PS, Gordon FD, et al. A model to predict poor survival in patients undergoing transjugular intrahepatic portosystemic shunts. Hepatology 2000;31:864-71.

53. Kamath PS, Wiesner RH, Malinchoc M, et al. A model to predict survival in patients with end-stage liver disease. Hepatology 2001;33:464-70.

54. Brown RS Jr, Kumar KS, Russo MW, et al. Model for end-stage liver disease and Child-Turcotte-Pugh score as predictors of pretransplantation disease severity, posttransplantation outcome, and resource utilization in United Network for Organ Sharing status 2A patients. Liver Transpl 2002;8:278-84.

55. Johnson PJ, Berhane S, Kagebayashi C, et al. Assessment of liver function in patients with hepatocellular carcinoma: a new evidence-based approach-the ALBI grade. J Clin Oncol 2015;33:550-8.

56. Molina V, Sampson-Dávila J, Ferrer J, et al. Benefits of laparoscopic liver resection in patients with hepatocellular carcinoma and portal hypertension: a case-matched study. Surg Endosc 2018;32:2345-54.

57. Morise Z, Isetani $M$, Kawabe $N$, et al. Case report of the fourth laparoscopic liver resection and review of repeat laparoscopic resection for recurrent hepatocellular carcinoma in cirrhotic liver. Hepatoma Res 2016;2:253-8. 